\title{
Radical Prostatectomy: Evolution of Surgical Technique from the Laparoscopic Point of View
}

\author{
Xavier Cathelineau, Rafael Sanchez-Salas, Eric Barret, Francois Rozet, Marc Galiano, Nicolas \\ Benoist, Oleksandr Stakhovsky, Guy Vallancien
}

Department of Urology, Institut Montsouris, Université Paris Descartes, Paris, France

\begin{abstract}
Purpose: To review the literature and present a current picture of the evolution in radical prostatectomy from the laparoscopic point of view.

Materials and Methods: We conducted an extensive Medline literature search. Articles obtained regarding laparoscopic radical prostatectomy (LRP) and our experience at Institut Montsouris were used for reassessing anatomical and technical issues in radical prostatectomy.

Results: LRP nuances were reassessed by surgical teams in order to verify possible weaknesses in their performance. Our basic approach was to carefully study the anatomy and pioneer open surgery descriptions in order to standardized and master a technique. The learning curve is presented in terms of an objective evaluation of outcomes for cancer control and functional results. In terms of technique-outcomes, there are several key elements in radical prostatectomy, such as dorsal vein control-apex exposure and nerve sparing with particular implications in oncological and functional results. Major variations among the surgical teams' performance and follow-up prevented objective comparisons in radical prostatectomy. The remarkable evolution of LRP needs to be supported by comprehensive results.

Conclusions: Radical prostatectomy is a complex surgical operation with difficult objectives. Surgical technique should be standardized in order to allow an adequate and reliable performance in all settings, keeping in mind that cancer control remains the primary objective. Reassessing anatomy and a return to basics in surgical technique is the means to improve outcomes and overcome the difficult task of the learning curve, especially in minimally access urological surgery.
\end{abstract}

Key words: prostatectomy; laparoscopy; minimally invasive; outcomes

Int Braz J Urol. 2010; 36: 129-40

\section{INTRODUCTION}

Radical prostatectomy (RP) remains the gold standard for the surgical treatment of localized prostate cancer. Evolution of the technique was started by the pioneering work done by Walsh and Donker (1). The accurate description of the dorsal vein complex, pelvic plexus and cavernous nerves and pelvic fascia has had a real impact in a number of patients operated for prostate cancer as regards morbidity and mortal- ity procedure and scientific investigation in prostatic carcinoma (2). Schuessler et al. (3) described their initial experience in laparoscopic radical prostatectomy (LRP), which they initially considered as having no benefits when compared to its open surgery counterpart.

However, they rationalized that technical progress and experience could improve results. In 1998, the Montsouris team began their experience in LRP with their own developed technique. LRP 
technique was well standardized (4); however, changes have been gradually introduced as a natural evolution of our surgical performance. The objective was to meet the demanding oncologic and functional objectives of the procedure and verify the efficacy of our technique. Our aim was to update the latest advances in our technique for LRP, at a point where our team had evolved from the steep learning curve of the procedure and arrived at a plateau level in which revaluation and improvement became mandatory.

\section{UNDERSTANDING THE ANATOMY OF THE PROSTATE AND ITS IMPLICATIONS ON SURGICAL TECHNIQUE}

Whether RP is performed in open surgery, laparoscopic or perineal, the anatomy of the gland remains the cornerstone of surgery. Comprehensive understanding of the anatomical landmarks and its implications in the patient's future quality of life are mandatory when attempting the procedure. This issue has propelled a rather wide range of surgical descriptions that subsequently produced a controversy in the anatomic nomenclature. In fact, the endopelvic fascia is also described as: lateral pelvic fascia or parietal layer of the pelvic fascia; the levator fascia is mentioned as outer layer periprostatic fascia and the prostatic fascia is also known as inner layer of periprostatic fascia (5). Furthermore, the arrival of laparoscopy presented the possibility of a magnified surgical field that has allowed urologic surgeons to verify prostatic anatomy and this has also contributed to extensive discussion (6).

\section{OPTIMAL SURGICAL TECHNIQUE}

Once the surgical field has been developed, as described by Barré, RP can be summarized in the stages described in Table-1 (7). Laparoscopic and robotic approaches have specific variations, which are shown in Table-1.

We are still far from the well known "Trifecta" ideal combination of oncologic success and adequate continence and potency (8), because even when patients should be comprehensively selected for surgery, a great number of particular variations still remain for each patient, including: large prostate, post transurethral resection setting and the obese patient. The best performances of RRP or LRP show a 11-14\% of positive margins, in 50 to $70 \%$ of patients with early continence and a maximum of $70 \%$ of patients with potency at one year follow-up (4-8).

\section{CONTINENCE PRESERVATION TECHNIQUE}

\section{Ligation of the Dorsal Vein}

The dorsal vein complex (DVC) approach, aims to reduce blood loss and also to improve functional continence results. As described by Olerich (9), the sphincter complex (SC) responsible for passive urinary control, covers the prostate apex. Therefore, DVC and SC are parallel and transection of the DVC could eventually be excised at the anterior portion of the sphincter with a definite impact in postoperative continence improvement $(10,11)$. For that reason, careful and elective ligation should be achieved in order to expose the prostatic apex and urethra (Figures-1 and 2).

\section{Dissection of the Apex}

Apex dissection should be approached with the idea of avoiding both areas by leaving prostatic tissue behind and not damaging the striated sphincter. Once the endopelvic fascia is incised and the puboprostatic ligaments transected, careful dissection to free the muscle fibers from the apex should be performed. Careful observation of the shape of the prostate is important to delineate the borders and therefore guide dissection $(2,7)$, keeping in mind that at the apical region nerve fibers run at 3 and 9 o'clock positions posterolaterally to the urethra (11) (Figure3).

Nguyen et al. (12) have proposed posterior reconstruction of Denonvilliers' musculofascial plate (PRDMP) to enhance early continence after robotic or laparoscopic radical prostatectomy. These authors suggest that PRDMP leads to improved maintenance 
Table 1 - Retropubic, laparoscopic and robotic assisted radical prostatectomy techniques.

\begin{tabular}{|c|c|c|}
\hline $\begin{array}{l}\text { Open Radical Prostatectomy } \\
\text { (Extraperitoneal) Barré (7) }\end{array}$ & $\begin{array}{c}\text { Laparoscopic Radical Prostatectomy } \\
\text { (Transperitoneal) Institut Montsouris } \\
\text { Initial Technique }\end{array}$ & $\begin{array}{c}\text { Robotic Assisted Radical } \\
\text { Prostatectomy (Transperitoneal) } \\
\text { Kaul \& Menon (19) }\end{array}$ \\
\hline \multicolumn{3}{|c|}{ Bilateral pelvic lymphadenectomy is selectively performed based on Gleason grade and PSA } \\
\hline 1. Incision and es & $\begin{array}{l}\text { 1. Dissection of the seminal vesicles, } \\
\text { via direct approach. }\end{array}$ & $\begin{array}{l}\text { 1. Peritoneoscopy and mobilization of } \\
\text { the bladder }\end{array}$ \\
\hline 2. Exposure of the prostate apex & $\begin{array}{l}\text { 2. Dissection of the bladder to approach } \\
\text { the space of Retzius }\end{array}$ & $\begin{array}{l}\text { 2. Preservation of endopelvic fascia } \\
\text { and control of dorsal venous com- } \\
\text { plex. Prostatic fascia preservation. }\end{array}$ \\
\hline $\begin{array}{l}\text { 3. Preservation of the striated } \\
\text { sphincter (Control of dorsal } \\
\text { vein) }\end{array}$ & 3. Dissection of the bladder neck & $\begin{array}{l}\text { 3. Dissection and division of the blad- } \\
\text { der neck }\end{array}$ \\
\hline $\begin{array}{l}\text { 4. Nerve-sparing (retrograde, } \\
\text { interfascial). Using clips for } \\
\text { hemostasis. }\end{array}$ & $\begin{array}{l}\text { ice between the rectum } \\
\text { te. }\end{array}$ & $\begin{array}{l}\text { of vas deferens and semi- } \\
\text { es }\end{array}$ \\
\hline $\begin{array}{l}\text { 5. Dissection of the seminal } \\
\text { vesicles and division of the } \\
\text { bladder neck }\end{array}$ & $\begin{array}{l}\text { 5. Control of dorsal vein complex, ex- } \\
\text { posure and dissection of the prostate } \\
\text { apex and urethra. }\end{array}$ & $\begin{array}{l}\text { 5. Nerve sparing (ante } \\
\text { cial), athermal techn }\end{array}$ \\
\hline $\begin{array}{l}\text { 6. Excision of the seminal vesi- } \\
\text { cles }\end{array}$ & $\begin{array}{l}\text { 6. Nerve sparing (antegrade, intrafas- } \\
\text { cial). Using clips and micro bipolar } \\
\text { energy. }\end{array}$ & $\begin{array}{l}\text { 6. Apical dissection and urethral trans- } \\
\text { action. }\end{array}$ \\
\hline $\begin{array}{l}\text { 7. Extraction and inspection of } \\
\text { the specimen }\end{array}$ & $\begin{array}{l}\text { 7. Extraction and inspection of the } \\
\text { specimen }\end{array}$ & $\begin{array}{l}\text { 7. Vesicourethral anastomosis (running } \\
\text { anastomosis) }\end{array}$ \\
\hline $\begin{array}{l}\text { 8. Vesicourethral anastomosis } \\
\text { (separate stitches) }\end{array}$ & $\begin{array}{l}\text { 8. Vesicourethral anastomosis (separate } \\
\text { stitches) }\end{array}$ & 8. Retrieval of the specimen \\
\hline
\end{tabular}

of membranous urethral length and significantly higher early continence rates.

\section{NERVE SPARING TECHNIQUE: MARGINS VS. POTENCY. ON WHICH SIDE OF THE FASCIA DO WE STAND?}

Walsh et al. have stated that: "The Lateral fascia is divided into 2 layers - the prostatic fascia and the levator fascia- and when the nerve sparing is properly performed the prostatic fascia must remain on the prostate" (13). The distinction between intrafascial, interfascial and extrafascial dissection has been described by open surgery surgeons $(1,7)$, however there is still controversy as to whether or not a clear distinction of the layers of tissue can be accomplished by open surgery, even by using operating loupes (6). As described by MartínezPiñeiro et al., (14) the interfascial plane would be a plane between the prostatic fascia and Denonvilliers fascia posterior and between the prostatic fascia and the anterior extension of Denonvilliers' fascia at the posterolateral aspect of the prostate.

In our experience, we have been able to obtain a highly detailed view of the anatomy with the endoscopic approach and more recently, lenses provided by the robotic interface do in fact improve the surgical field due to a three-dimensional perspective. Although the improvements accomplished since Walsh's first operation over 25 years ago, radical prostatectomy remains a challenging procedure with a steep learning curve and two objectives that are contradictory. The idea is to obtain reliable cancer 


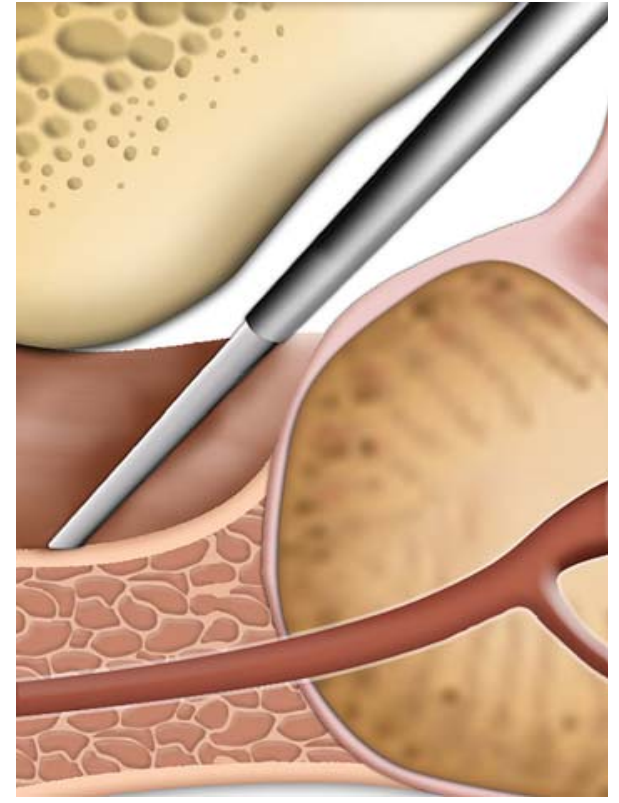

Figure 1 - Clamping and cutting of dorsal vein complex.

control, which means avoidance of positive surgical margins while preserving as much as possible functionality in terms of continence and potency. Excellent rates of cancer control for patients with organ-confined disease (5-year recurrence free probabilities close to $100 \%$ ) are accomplished by dedicated surgeons only when a surgical technique is properly performed (15). Complete preservation of the neurovascular bundles (NVB) is performed either with intrafascial or interfascial dissection technique (6), however, we believe that the interfascial plane would be the elected plane for comprehensive nerve sparing in order to be oncologically safe while preserving functionality (Figures-4 and 5). Secin et al., (16) have described the intrafascial technique as the reference procedure for preservation of NVB in selected patients based on pre- and intraoperative findings. Several authors have also supported the idea of an intrafascial dissection (17-19). We agree that comprehensive and judicious preoperative evaluation and adequate interpretation of operative findings are crucial in final results of the prostatectomy, but there is also a need to state a technical approach that might not only spread LRP even more, but offer safety to

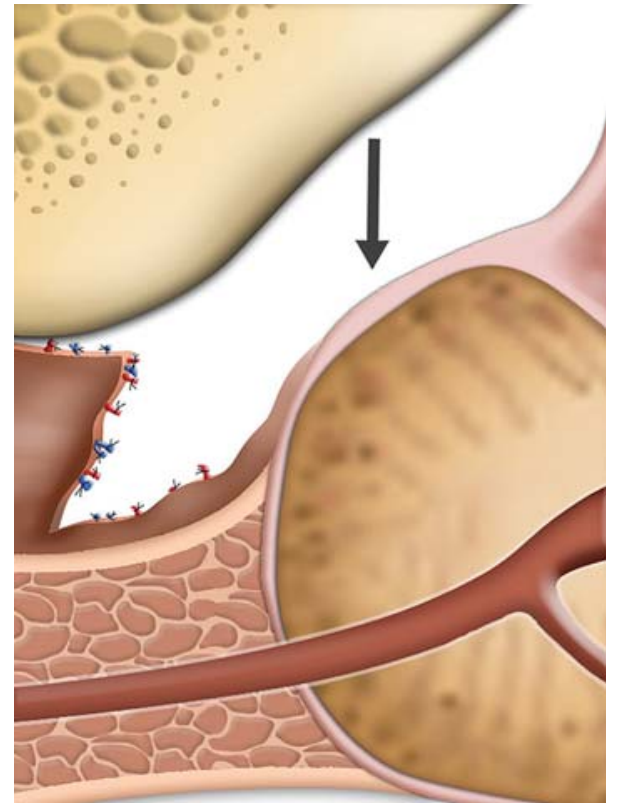

Figure 2 - Clamping and cutting of dorsal vein complex. Arrow shows placement of back bleeding control stitch.

patients in all settings. See Table-2 for variations on technique, approach and type of nerve sparing technique for radical prostatectomy.

\section{Antegrade and Retrograde Dissections}

There are two nerve sparing techniques, the antegrade dissection that starts at the base of the prostate and continues along the posterolateral contour to end in the posterior edge $(7,20)$, and the retrograde, which starts at the apex and develops a plane between the rectum and the prostate to expose the medial border of the NVB. Retrograde dissection was the initially described technique for RRP, and it is characterized by a high incision of the fascia. The antegrade dissection has been applied primarily in LRP and it has been criticized because of the starting point of dissection that can be rather high, creating an intrafascial dissection, or very low, which would injure the nerves (7). In the principles of interfascial dissection of the NVB, skilled dissection and avoiding energy sources around the NVB are more important factors than the nerve-preservation technique used (20). 


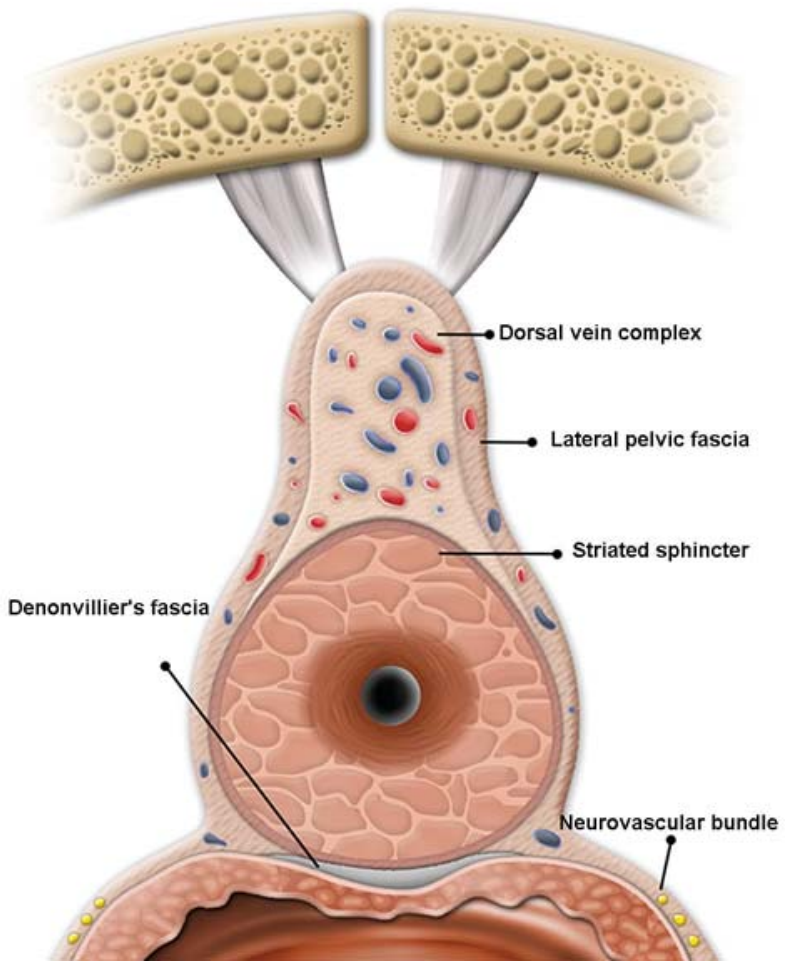

Figure 3 - Diagram showing urethra and its relations with dorsal vein complex.

\section{ANATOMICAL RATIONALE FOR A PROSTATIC VEIL}

There is objective evidence that supports the fact of the existence of a neurovascular network that surrounds the prostate and that it could have an impact in postoperatory evaluated issues. However, the idea of giving it a cumbersome name, has just add more to the already crowded world of nomenclature in radical prostatectomy and therefore we agree with Rassweiler [5] to avoid using the socalled term "Veil of Aphrodite". Ganzer et al. (21) have objectively verified that the highest percentage (74-84\%) of the total nerve surface of the prostate is located dorsolaterally, with up to $39 \%$ of nerve surface area, found ventrolaterally. In their study, computerized planimetry offered a basic view that periprostatic nerve distribution is variable with a high percentage of nerves in the ventrolateral and dorsal position. They also verified an interesting decrease

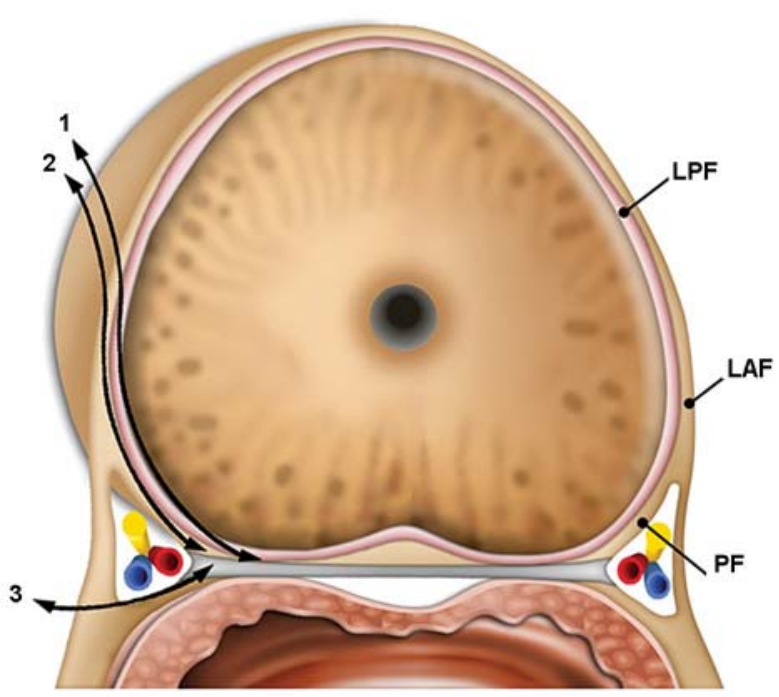

Figure 4 - Neurovascular bundle sparing.

in total periprostatic nerve surface area from the base to the apex. Several researchers have also addressed the subject of periprostatic nerve distribution with comparable results in terms of most frequent localization of nerves (dorsolaterally) and a high percentage of variation from case to case (22-24).

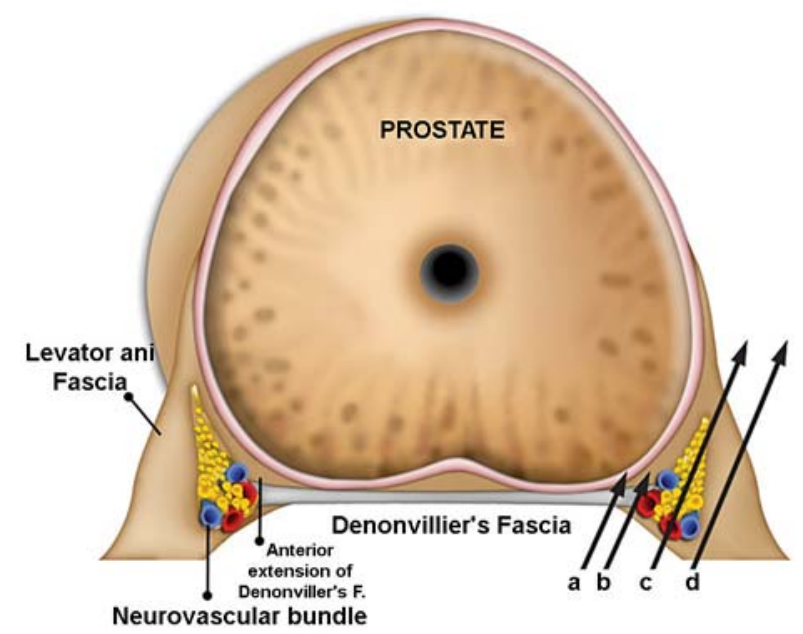

Figure 5-Grades of neurovascular bundle preservation. 
Radical Prostatectomy

Table 2 - Variations on technique, approach and type of nerve sparing for radical prostatectomy.

\begin{tabular}{lcc}
\hline Authors & Radical Prostatectomy Technique & Type of Nerve Sparing \\
\hline Barré C (7) & Open/extraperitoneal & Retrograde/Interfascial \\
Secin et al. (16) & Laparoscopic/transperitoneal & Antegrade/Intrafascial \\
Stolzenburg et al. (37) & Laparoscopic/extraperitoneal & Antegrade/Intrafascial \\
Kaul \& Menon (19) & Robotic assisted Laparoscopy & Antegrade/Intrafascial \\
Institut Montsouris 2008 & Laparoscopic or robotic, extraperitoneal & Antegrade/ Interfascial \\
\hline
\end{tabular}

\section{ROBOTIC INTERFACE OFFERINGS FOR RADICAL PROSTATECTOMY LEARNING CURVE}

As we have previously mentioned, laparoscopic radical prostatectomy far from dying is rapidly evolving (25). The use of the robot has reduced the learning curve due to EndoWrist ${ }^{\circledR}$ technology, threedimensional imaging and magnification but there is still a need for solid evidence to back up the analysis of the learning curve, as completing the procedure or being able to perform it does not necessarily mean it is done well. The robot represents a useful instrument for the surgeon and it should be regarded as a procedure to be followed in the future, as its results will certainly improve in the years to come.

Meanwhile, how many cases do we need to become expert surgeons in the technique we perform on a daily basis? or perhaps more importantly, how many cases do the fellows standing by our sides need to become safe and reliable operators?

These remain controversial questions that we still need to address, not only in radical prostatectomy but also as regards minimal urological access surgery. The arrival of both, laparoscopy and more recently the robotic interface has focused our attention on the term learning curve. In fact, laparoscopic series brought with it a tremendous enthusiasm in terms of validation of the technique and therefore extensive work in the procedure's learning curve.

Is there a formal definition for learning curve? Probably not. However, let us see:

The Ross procedure is a challenging operation for patients with aortic valve disease. The principle is to remove the patient's normal pulmonary valve and used it to replace the patient's diseased aortic valve. In Dr. Ross's own series, $23 \%$ of the patients died during the first year of the operation and $18 \%$ in the second year. In the following 10 years, the surgical mortality in a series of 188 patients dropped to $9 \%$. This is a learning curve. The message: It requires time and hard work (26). The incorporation of new devices into surgical practice such as the robot - requires that surgeons acquire and master new skills. As in any new technology, robotic surgery demands dedication to achieve expertise. For a skilled laparoscopic surgeon the learning curve to achieve proficiency with robotic radical prostatectomy is estimated at between 40 to 60 cases. For the laparoscopically naive surgeon the curve is estimated at 80 to 100 cases (27). The Da Vinci assisted approach incorporates the advantages of minimally invasive approach while presenting comparable results to the open surgical approach. However, we do not believe that proficiency could be achieved within the first 20 or 25 cases of robotic experience, as has previously been stated (28). Robotic interface appears to offer a significant benefit to the laparoscopically naive surgeon with respect to learning curve, at an increased cost. We have previously demonstrated that laparoscopic extraperitoneal radical prostatectomy is equivalent to the robotic assisted laparoscopic prostatectomy in the hands of skilled laparoscopic urological surgeons with respect to operative time, operative blood loss, hospital stay, length of bladder catheterization and positive margin rate (29). Improvement of our technique is found on a daily basis and there is considerable experience needed to reach the best quality in both open and laparoscopic standards. The latter is in agreement with 
the study by Vickers et al. in their timely publication assessing surgical learning curve for prostate cancer control (30). These investigators found a statistical significance related to the surgeon's experience and cancer control after radical prostatectomy. This study is a return to the basic concept of learning curves and suggests a real link between surgical technique and cancer control. Its analysis showed a dramatic improvement in cancer control with increasing surgeon experience up to 250 previous treated cases. As presented in a recent review of the robotic literature by Ficarra et al., positive surgical margin rates decreased with the surgeon's experience and improvement in technique; reaching percentages similar to those of retropubic and laparoscopic series (31).

Establishing a robotic prostatectomy program is an important challenge to any institution requiring both financial support and a focused operating room team (32), but this must not lead to an aggressive patient acquisition (advertising, commercialization) during the basic learning curve, because cancer care implies offering a product of the highest quality. The learning curve plateaus come with training and experience. Surgeons have always recognized a structured way to introduce new procedures and learning a new technique requires dedication. Unfortunately, as reported by Tooher et al., (33) the laparoscopic learning curve has only been addressed in a limited number of studies.

\section{NEED FOR REVISION AND STANDARDIZATION}

As recently described, oncological outcomes after radical prostatectomy improve with the surgeon's experience irrespective of patient risk and inadequate surgical technique leads to recurrence (34). It has been recently reported that patients undergoing minimally access prostatectomy (either pure lap or robotic assisted) vs. open radical prostatectomy (ORP) have a lower risk for perioperative complications and shorter lengths of stay, but they harbor higher probability for salvage therapy and anastomotic strictures (35). These unfavorable outcomes would be diminished by high surgical volume. The main limitation of this study was the comparison of surgical teams that do not necessarily represent the standard of care in both open and laparoscopic technique. Therefore, the aim is to improve LRP surgical technique and take advantage of the novel surgical instruments to guarantee a solid based concept of minimally access surgery as the most adequate therapeutic option for localized prostate cancer. As described by Touijer and Guillonneau (36) even when all the reports agree and demonstrate the benefits of minimal access surgery, there are no prospective series comparing LRP vs. ORP and there are important variations reported in the characteristics of the procedure: whether or not performing lymph node dissection, a wide range of positive margin rates $(6 \%$ to $8 \%$ for organ-confined disease and from $35 \%$ to $60 \%$ with extraprostatic extension), lack of evaluation of short term biochemical recurrence and extreme variations in the evaluation and reporting of functional outcomes. Going back to basics, in our understanding, is a reevaluation and deployment of a surgical technique based on both the available knowledge of the subject and experience. Stolzenburg et al. have opened the way in this matter with their recent experience of extraperitoneal LRP with intrafascial dissection, in which they report a low frequency of surgical margins with $80 \%$ and $94 \%$ of potency and continence, respectively (37). However, Tooher et al. in their systematic review of comparative studies report that stronger evidence is needed when comparing LRP vs. RRP. There is still a desire in the medical community for a randomized control study and LRP still remains as the emerging alternative for the surgical treatment of localized prostate cancer (33).

\section{LRP MONTSOURIS TECHNIQUE}

Five trocars are used (three $5 \mathrm{~mm}$, two 10 $\mathrm{mm}$ ), one in the umbilicus and the others in the iliac fossa. There are no significant differences between the Trans- or extraperitoneal approach as we have previously described (38), however currently we usually perform an extraperitoneal approach with balloon dissection under direct visualization and insufflation of the space, which creates an optimal operative field. Trocars are positioned according to surgeon's preference. Bilateral pelvic lymph node dissection is performed when it is indicated (PSA values $>10$ $\mathrm{ng} / \mathrm{mL}$ and Gleason score $>7$ on primary prostatic 
Table 3 - Montsouris technique for laparoscopic radical prostatectomy.

Positioning

Surgical approach, creation of surgical field and trocar positioning

Incision of the endopelvic fascia

Division of bladder neck and dissection of the seminal vesicles.
Patient is placed in moderate Trendelenburg position with adequate padding and covering on the areas of exposure.

Extraperitoneal approach with balloon dissection under direct visualization and insufflation of the space, creates an optimal operative field. Trocars are positioned according to surgeon's preference.

Bilateral incisions are performed from the prostate base to the puboprostatic ligaments. Levator ani fibers should be gently mobilized and spared from either side of the prostate. This maneuver should avoid the disruption of venous pedicles usually present in the area. Puboprostatic ligaments are sectioned close to its prostate attachment, sparring its attachment to the sphincter complex.

Starting in the pericervical area, the bladder neck is carefully dissected towards the prostate delineating the urethral fibers. Bipolar hemostasis should be precise during this step to avoid excessive blood loss. Our aim when possible is to preserve the bladder neck. The anterior wall of the bladder neck is incised and we proceed to find the plane between the posterior wall of the bladder neck and the prostate. This dissection is made in the extending muscle fibers from the detrusor muscle. In cases of a median lobe a reconstruction should be performed. Once the posterior wall of the bladder neck is dissected, we encounter anterior layers of Denonvilliers' fascia, that are incised in order to reach both vas deferens that should be dissected and ligated. Gently traction in the distal end of each vas aids in exposing the seminal vesicles for their dissection. Once again, a reliable hemostasis should be accomplished and dissection is undertaken close the wall of the vesicles. One must remember that the tip of the seminal vesicle is just above the plane of the neurovascular bundle in order to avoid going too wide in the dissection.

Posterior surface of the prostate should be carefully dissected to create a space between the gland and the rectum. This maneuver will create a "tunnel" under the prostate gland, which demarks the neurovascular bundles at each side. Antegrade dissection starts at the posterior surface of the prostate and goes along the posterolateral contour of the gland. Traction for exposure should be carefully applied to avoid affecting the neurovascular bundles. We agree with the initial pioneer description by Walsh, that as the lateral fascia divides into 2 layers - the prostatic fascia and the levator fascia- nerve sparing is properly performed when the prostatic fascia remains on the prostate, so we perform an interfascial dissection -between the parietal(levator) and visceral(prostatic) fascia- in order to avoid positive surgical margins while preserving potency. There are two key points in the dissection:

1. Posterolateral incision of Denonvilliers' fascia.

2. Lateral incision of the levator ani fascia, keeping in mind that initial section should be performed at 2-3 o'clock position and 9-10 for the right and left prostatic sides, respectively. 
Table 3 - Montsouris technique for laparoscopic radical prostatectomy. (continued)

Dorsal vein control and apex exposure

Extraction and inspection of the specimen

Vesicourethral anastomosis
We performed a stitch over the anterior surface of the prostate to stop back bleeding, then, we proceed to clamp the dorsal vein above the striated sphincter $( \pm 15 \mathrm{~mm}$ depth$)$ and incise the dorsal vein complex with cold scissors. A control bleeding stitch is placed behind the clamp, avoiding going deep in order to protect anterior part of the sphincter. Remaining portion of the dorsal vein is divided under direct vision and hemostasis accomplished with superficial stitches (Vicryl ${ }^{\circledR} 2-0$ ). This, exposes the prostate apex and the urethra's surrounding sphincter. Extensive dissection at the lateral sides of the apex is avoided. The urethra is divided step by step, in order to visualize the muscle fibers of the sphincter and its relations with the apex. After the urethra is fully transected, the apex dissection is carefully accomplished in both the anterior and posterior surfaces of the prostate, aiming to avoid excessive traction.

The specimen is extracted and verified by the surgical team. Frozen section if indicated.

It is performed with separate Vicryl ${ }^{\circledR} 3-0$ stitches and 5/8 needle, starting in the posterior wall and going from side to side, until completing a watertight closure (verified by fulfilling the bladder with $80 \mathrm{cc}$ of solution). During the anastomosis both the grade of Trendelenburg position and also the pneumoperitoneum are decreased. biopsy) $(39,40)$. In such cases, we rather perform a transperitoneal approach for the procedure. Table-3 shows a detailed description of the most recent surgical technique performed at our institution.

\section{POINTS OF CHANGE. STAYS AND GOES}

It has been over 25 years since the Walsh and Donker anatomical description and over 10 years since the Montsouris experience in LRP started. The rapid evolution of surgical technique has been the rule and several variations for RP have been described. After years of experience, we would like to share the elements of the operation that we have kept overtime and others that we have discarded.

Stays:

- Opening of the pelvic fascia.

- Preservation of the bladder neck for cases with negatives biopsies at prostatic base.

- Effective hemostasis by means of small clips and elective micro bipolar energy.

- Antegrade nerve sparing dissection.

Goes:

- Direct dissection of the seminal vesicles after incising the peritoneum above the pouch of Douglas

- Deep stitching without clamping of the dorsal vein complex to accomplish hemostasis.

- Extensive lateral dissection of the apex and urethra.

- Intrafascial dissection during nerve sparing.

\section{CONCLUSIONS}

Radical prostatectomy is a complex surgical operation with difficult objectives; surgical technique should be standardized in order to allow an adequate 
and reliable performance in all settings, keeping in mind that cancer control remains objective number one. There is no unique way to attain the highest surgical quality (open or lap, antegrade or retrograde, intra- or interfascial), but there are several concepts and rules to be followed. Reassessing anatomy and going back to basics in surgical technique is the path to improve outcomes and overcome the difficult task of learning curve.

\section{ACKNOWLEDGEMENT} in the figures.

Miss Julia Dasic performed the artistic work

\section{CONFLICT OF INTEREST}

None declared.

\section{REFERENCES}

1. Walsh PC, Donker PJ: Impotence following radical prostatectomy: insight into etiology and prevention. J Urol. 1982; 128: 492-7.

2. Walsh PC: The discovery of the cavernous nerves and development of nerve sparing radical retropubic prostatectomy. J Urol. 2007; 177: 1632-5.

3. Schuessler WW, Schulam PG, Clayman RV, Kavoussi LR: Laparoscopic radical prostatectomy: initial shortterm experience. Urology. 1997; 50: 854-7.

4. Guillonneau B, Vallancien G: Laparoscopic radical prostatectomy: the Montsouris technique. J Urol. 2000; 163: 1643-9.

5. Rassweiler J: Intrafascial nerve-sparing laproscopic radical prostatectomy: do we really preserve relevant nerve-fibres? Eur Urol. 2006; 49: 955-7.

6. Martínez-Piñeiro L: Prostatic fascial anatomy and positive surgical margins in laparoscopic radical prostatectomy. Eur Urol. 2007; 51: 598-600.

7. Barré C: Open radical retropubic prostatectomy. Eur Urol. 2007; 52: 71-80.

8. Bianco FJ Jr, Scardino PT, Eastham JA: Radical prostatectomy: long-term cancer control and recovery of sexual and urinary function ("trifecta"). Urology. 2005; 66 (5 Suppl): 83-94.
9. Oelrich TM: The urethral sphincter muscle in the male. Am J Anat. 1980; 158: 229-46.

10. Stolzenburg JU, Schwalenberg T, Horn LC, Neuhaus J, Constantinides C, Liatsikos EN: Anatomical landmarks of radical prostatecomy. Eur Urol. 2007; 51: 629-39.

11. Heidenreich A: Radical prostatectomy in 2007: oncologic control and preservation of functional integrity. Eur Urol. 2008; 53: 877-9.

12. Nguyen MM, Kamoi K, Stein RJ, Aron M, Hafron JM, Turna B, et al.: Early continence outcomes of posterior musculofascial plate reconstruction during robotic and laparoscopic prostatectomy. BJU Int. 2008; 101: 1135-9.

13. Walsh PC, Lepor H, Eggleston JC: Radical prostatectomy with preservation of sexual function: anatomical and pathological considerations. Prostate. 1983; 4: 473-85.

14. Martínez-Piñeiro L, Cansino JR, Sanchez C, Tabernero A, Cisneros J, de la Peña JJ: Laparoscopic radical prostatectomy. Differences between the interfascialand the intrafascial technique. Eur Urol Suppl. 2006; 5: 331.

15. Vickers AJ, Bianco FJ, Gonen M, Cronin AM, Eastham JA, Schrag D, et al.: Effects of pathologic stage on the learning curve for radical prostatectomy: evidence that recurrence in organ-confined cancer is largely related to inadequate surgical technique. Eur Urol. 2008; 53: 960-6.

16. Secin FP, Serio A, Bianco FJ Jr, Karanikolas NT, Kuroiwa K, Vickers A, et al.: Preoperative and intraoperative risk factors for side-specific positive surgical margins in laparoscopic radical prostatectomy for prostate cancer. Eur Urol. 2007; 51: 764-71.

17. Curto F, Benijts J, Pansadoro A, Barmoshe S, Hoepffner JL, Mugnier C, et al.: Nerve sparing laparoscopic radical prostatectomy: our technique. Eur Urol. 2006; 49: 344-52.

18. Stolzenburg JU, Rabenalt R, Tannapfel A, Liatsikos EN: Intrafascial nerve-sparing endoscopic extraperitoneal radical prostatectomy. Urology. 2006; 67: 17-21.

19. Menon M, Kaul S, Bhandari A, Shrivastava A, Tewari A, Hemal A: Potency following robotic radical prostatectomy: a questionnaire based analysis of outcomes after conventional nerve sparing and prostatic fascia sparing techniques. J Urol. 2005; 174: 2291-6, discussion 2296.

20. Rassweiler J, Wagner AA, Moazin M, Gözen AS, Teber D, Frede T, Su LM: Anatomic nerve-sparing laparoscopic radical prostatectomy: comparison of retrograde and antegrade techniques. Urology. 2006; 68: 587-91; discussion 591-2. 
21. Ganzer R, Blana A, Gaumann A, Stolzenburg JU, Rabenalt R, Bach T, et al.: Topographical anatomy of periprostatic and capsular nerves: quantification and computerised planimetry. Eur Urol. 2008; 54: 35360.

22. Lunacek A, Schwentner C, Fritsch H, Bartsch G, Strasser H: Anatomical radical retropubic prostatectomy: 'curtain dissection' of the neurovascular bundle. BJU Int. 2005; 95: 1226-31.

23. Kiyoshima K, Yokomizo A, Yoshida T, Tomita K, Yonemasu H, Nakamura M, et al.: Anatomical features of periprostatic tissue and its surroundings: a histological analysis of 79 radical retropubic prostatectomy specimens. Jpn J Clin Oncol. 2004; 34: 463-8.

24. Eichelberg C, Erbersdobler A, Michl U, Schlomm T, Salomon G, Graefen M, et al.: Nerve distribution along the prostatic capsule. Eur Urol. 2007; 51: 10510; discussion 110-1.

25. Cathelineau X, Sanchez-Salas R, Barret E, Rozet F, Vallancien G: Is laparoscopy dying for radical prostatectomy? Curr Urol Rep. 2008; 9: 97-100.

26. Hasan A, Pozzi M, Hamilton JR: New surgical procedures: can we minimise the learning curve? BMJ. 2000; 320: 171-3.

27. Ahlering TE, Skarecky D, Lee D, Clayman RV: Successful transfer of open surgical skills to a laparoscopic environment using a robotic interface: initial experience with laparoscopic radical prostatectomy. J Urol. 2003; 170: 1738-41.

28. Samadi D, Levinson A, Hakimi A, Shabsigh R, Benson $\mathrm{MC}$ : From proficiency to expert, when does the learning curve for robotic-assisted prostatectomies plateau? The Columbia University experience. World J Urol. 2007; 25: 105-10.

29. Rozet F, Jaffe J, Braud G, Harmon J, Cathelineau X, Barret E, Vallancien G: A direct comparison of robotic assisted versus pure laparoscopic radical prostatectomy: a single institution experience. J Urol. 2007; 178: 478-82.

30. Vickers AJ, Bianco FJ, Serio AM, Eastham JA, Schrag D, Klein EA, et al.: The surgical learning curve for prostate cancer control after radical prostatectomy. J Natl Cancer Inst. 2007; 99: 1171-7.

31. Ficarra V, Cavalleri S, Novara G, Aragona M, Artibani W: Evidence from robot-assisted laparoscopic radical prostatectomy: a systematic review. Eur Urol. 2007; 51: 45-55; discussion 56.

32. Badani KK, Hemal AK, Peabody JO, Menon M: Robotic radical prostatectomy: the Vattikuti Urology Institute training experience. World J Urol. 2006; 24 : 148-51.
33. Tooher R, Swindle P, Woo H, Miller J, Maddern G: Laparoscopic radical prostatectomy for localized prostate cancer: a systematic review of comparative studies. J Urol. 2006; 175: 2011-7.

34. Klein EA, Bianco FJ, Serio AM, Eastham JA, Kattan MW, Pontes JE, et al.: Surgeon experience is strongly associated with biochemical recurrence after radical prostatectomy for all preoperative risk categories. J Urol. 2008; 179: 2212-6; discussion 2216-7.

35. Hu JC, Wang Q, Pashos CL, Lipsitz SR, Keating NL: Utilization and outcomes of minimally invasive radical prostatectomy. J Clin Oncol. 2008; 26: 2278-84.

36. Touijer K, Guillonneau B: Laparoscopic radical prostatectomy: a critical analysis of surgical quality. Eur Urol. 2006; 49: 625-32.

37. Stolzenburg JU, Rabenalt R, Do M, Schwalenberg T, Winkler M, Dietel A, et al.: Intrafascial nerve-sparing endoscopic extraperitoneal radical prostatectomy. Eur Urol. 2008; 53: 931-40.

38. Cathelineau X, Cahill D, Widmer H, Rozet F, Baumert H, Vallancien G: Transperitoneal or extraperitoneal approach for laparoscopic radical prostatectomy: a false debate over a real challenge. J Urol. 2004; 171 : 714-6.

39. Bishoff JT, Reyes A, Thompson IM, Harris MJ, St Clair SR, Gomella L, et al.: Pelvic lymphadenectomy can be omitted in selected patients with carcinoma of the prostate: development of a system of patient selection. Urology. 1995; 45: 270-4.

40. Partin AW, Yoo J, Carter HB, Pearson JD, Chan DW, Epstein JI, et al.: The use of prostate specific antigen, clinical stage and Gleason score to predict pathological stage in men with localized prostate cancer. J Urol. 1993; 150: 110-4.

Accepted after revision: September 26, 2009

\section{Correspondence address:}

Dr. Xavier Cathelineau

Department of Urology

Institut Montsouris

42, Bd Jourdan, 75014

Paris, France

Fax: + 0033156616641

E-mail: xavier.cathelineau@imm.org 


\section{EDITORIAL COMMENT}

Open radical prostatectomy is the gold standard and most widespread treatment for clinically localized prostate cancer. However, in recent years laparoscopic and robot-assisted laparoscopic prostatectomy has rapidly been gaining acceptance among urologists worldwide and has become an established treatment for organ-confined prostate cancer.

Schuessler et al. in 1997 (1), described the initial experience in laparoscopic radical prostatectomy (LRP), which they concluded that this technique did not provide any advantages over open surgery.

As the authors described in this revision, in 1998, the Montsouris team started their experience in LRP. LRP technique was well standardized and changes have been gradually introduced as a natural evolution of the technique.

A better understanding of the periprostatic anatomy and further modification of surgical technique will result in continued improvement in functional outcomes and oncological control for patients undergoing radical prostatectomy, whether by open or minimally-invasive surgery. The oncologic results are in line with those reported with the use of the retropubic approach (2).
Today patients diagnosed with clinically localized prostate cancer have more surgical treatment options than in the past including open, laparoscopic and robot-assisted laparoscopic radical prostatectomy.

However, cost-efficacy, learning curves and oncologic outcomes and remain important considerations in the dissemination of minimally-invasive prostate surgery.

\section{REFERENCES}

1. Schuessler WW, Schulam PG, Clayman RV, Kavoussi LR: Laparoscopic radical prostatectomy: initial shortterm experience. Urology. 1997; 50: 854-7.

2. Paul A, Ploussard G, Nicolaiew N, Xylinas E, Gillion N, de la Taille A, et al.: Oncologic Outcome after Extraperitoneal Laparoscopic Radical Prostatectomy: Midterm Follow-up of 1115 Procedures. Eur Urol. 2009; 17. [Epub ahead of print]

Dr. Mauricio Rubinstein Section of Urology Federal University of Rio de Janeiro State Rio de Janeiro, RJ, Brazil E-mail:mrubins74@hotmail.com 